\title{
Effects of openings on the seismic behavior and performance level of concrete shear walls
}

\author{
Hossein Alimohammadi, Mostafa Dalvi Esfahani, Mohammadali Lotfollahi Yaghin
}

\begin{abstract}
In this study, the seismic behaviour of the concrete shear wall considering the opening with different shapes and constant cross-section has been studied, and for this purpose, several shear walls are placed under the increasingly non-linear static analysis (Pushover). These case studies modelled in 3D Abaqus Software, and the results of the ductility coefficient, hardness, energy absorption, added resistance, the final shape, and the final resistance are compared to shear walls without opening.
\end{abstract}

Index Terms - Concrete Shear Wall, Seismic Parameters, Nonlinear Static Analysis, Performance levels, Pushover Diagrams

\section{INTRODUCTION}

One of the earthquake-resistant systems is a concrete shear wall system that due to its good performance in past earthquakes has been of interest to the engineers. But some architectural limitations enforced computing engineers to insert openings in its walls. Especially, in tall trellises with concrete core, a good location around lift lobby is suitable to install the shear wall and connect them to each other perpendicularly to create the winged shear walls, but in order to embed the elevator door we had to create openings in a wall that this matter will affect the behavior of shear wall. Reinforcement ratio and the Percentage of the wall opening dimensions of the most important factors affecting the nonlinear behavior of reinforced concrete shear walls with openings. Also, in recent decades, the steel shear wall system as one of the resistant systems against lateral loads has been paid attention by the researchers. Architectural requirements and beautification or non-structural considerations such as through mechanical installations and systems designers need to design or use thinner steel sheet steel with low yield strength may not be available in the market and the creation of factors that are causing the steel shear walls.

In previous studies, the coupled beams are used to model shear walls openings for computer modeling; this approximation, especially for low-level openings with a relatively large error, occurs in the structural response [1]

This research could probe to understand the seismic behavior of these structures under nonlinear load, also concerning the possibility of making different innovations in the building industry structures and the increasing need for such innovations as well as the lack of adequate information and analysis. In this regard, this study could identify further development of this type of structure in the construction industry.

Hossein Alimohammadi, Ph.D. student, Civil, Construction and Environmental Engineering Department, Iowa State University, Iowa, USA,

Mostafa Dalvi Esfahani, Master of Science, Civil engineering department, Azad university of Maragheh, East Azerbaijan, Iran,

Mohammadali Lotfollahi Yaghin, Professor, Civil Engineering Department, Tabriz University, Tabriz, East Azerbaijan, Iran.,
The study assumes a non-linear loading and linear and nonlinear behavior of the structure as well as a variety of openings' shapes down on the seismic behavior of shear wall structures have different effects (from flexibility, ultimate load, and stiffness and so on) [2].

\section{II. . BASICS OF DESIGN THEORY BASED ON NONLINEAR METHOD AND STRUCTURAL PERFORMANCE}

\section{A. Define some specifications seismic structures}

The behavior of structural members according to the curve of force-deformation under a controlled force or controlled deformation can be classified by force and are introduced based on three different behaviors including ductile, semi-ductile, and brittle behavior. Ductile behavior is a kind that its structure in that area is elastic, but brittle behavior is that structures are low with great difficulty and the distance between the stress and the yield [3].

Ductile structures where the gap between the end and yield stress is high and structures in the elastic area will continue to transport by a nonlinear behavior. Nonlinear deformation allows the structures less power compared to the linear elastic structure against earthquake, in Figure 1 pushover curve load-displacement curve is drawn to a structure.

Pushover analysis is a non-linear static analysis of the structure under lateral loads increasing and determining diagrams of load-displacement shift with a curve of the structural capacity of the quantities of base shear and lateral displacement that is usually used a reference level point for drawing the graph. Comparing to dynamical analysis, this method includes some more approximations. The dynamical method can analyze various behavior of structures such under various kind of loading, such as earthquakes, wind or considering some accidental failures in structures such as progressive collapse [4]. However, pushover analysis also can provide reliable performance of the structure, [5]. For example, Mousavi et al. used this method to investigate the ductility of concrete frames reinforced with high resistant steel bars. Utilizing pushover analysis, they successfully showed that using non-standard high-strength steel rebar can reduce the ductility of the frames. In another research, they used pushover analysis to study the effect of geometric parameters on response reduction factor $(\mathrm{R})$ of steel special truss moment frames (STMF), [6]. In this study the pushover curves are idealized to bilinear curves in a way that Mousavi et al. used in their research. The ductility coefficient $(\mu)$ is the structural capacity to withstand non-elastic and plastic deformations without collapsing structures. According to this description, it can be stated that the maximum displacement of non-linear structures $(\Delta \max )$ to shift of yield point $(\Delta y)$ is the coefficient of plasticity as shown in Eq 1. 


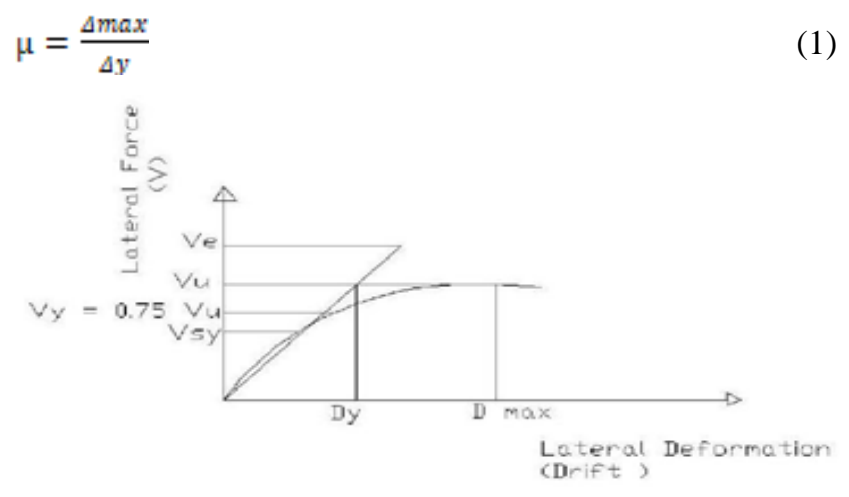

Figure 1 Pushover load-displacement curve of a sample of structures [7]

The added resistance coefficient of the shear panel is a factor of resistance in structural design codes, and a structure is tolerated more than designed resistance, and it is the ratio of ultimate strength to yield strength panel as illustrated in Eq 2 [2].

$$
\Omega=\frac{V u}{V y}
$$

\section{B. Necessity of seismic designing based on performance}

Earthquake engineering has been set under fundamental changes because of various reasons. Promotion of knowledge about earthquakes, land movements and structural properties as well as the results obtained from recent earthquakes in the United States and Japan led to losing the properties and played an important role in the changes. From the most important reasons is that in the existing method of designing the procedures the following cases are not sufficiently and logically addressed: 1) The purpose of the designer for a logical explanation of the laws that they had used to make the decision, 2) What the owners asked to judge the costs and benefits of making the resistant building against earthquakes, and 3) The needs of society to make conscious intentions based on stochastic seismic demand acted by shaking the land and uncertain seismic capacities in existing and modern buildings.

As a result of the severe earthquake, significant damages have been applied to the structures due to the non-elastic behavior of the building. That is why, according to the force-displacement in place, the structure caused by an intense earthquake. After passing into a non-elastic range at first, it is entered into an area with partial resistance changes in the strength and bent forms that have a close relationship with the damages [7].

In performance-based design, the performance of non-linear structural components was examined. This may be because of specifying the more actual behavior of structures than before, in case of the occurrence of a specified earthquake. Perhaps the most important reason for the importance of discussion about performance-based seismic design is depended on the type of initiative encouragement for the development of methods to enhance the performance. In the current guidelines, this procedure or encouragement to be initiative does not exist. The reason for this is that new concepts do not apply to a strict and closed framework of such guidelines [7].

\section{Objectives Regarding Performance Levels in Structures}

The essence of the concept of performance-based design requires defining the multiple levels of performance defined the target (losses), and it is expected that the structure under certain intensity earthquake to reach the level or at least it does not exceed these levels. A performance objective is to identify the desired performance level of the building in every level of earthquake designed and assigned. About a building, design performance objectives should be determined according to the reasons such as 1) Usage of the buildings, 2) The importance of building in terms of the activities associated with it, 3) Economic considerations, including costs related to repair the buildings and make use of the building to create a break in building operation, and 4) The value of building as a historical or cultural work [7]

Therefore, performance objectives determine the seismic performance of the structure, and the seismic performance is defined by the performance levels of the maximum allowable amount of damage to the structure for determining an earthquake. Besides, the aim of the operation may be considering the different scenarios for several seismic damages in which case it is defined as a dual and multi-purpose. As indicated by the purpose of performance, an earthquake engineer can select the seismic design and determine the acceptable criteria of non-structural and structural evaluation [8].

\section{The Principle Levels of Operation of Structures}

The principle levels of operation of structures consist of: 1) Immediate Occupancy (IO): any disorder in serving the policy of structures has not I have been made, 2) Life Safety (LS): the purpose of preserving the lives of the families and communities and structures may not be available after the earthquake, and 3) Collapse Prevention (CP): there is a limited risk of loss of lives [7]. In Figure 2, the concept of performance levels of the structures has been shown.

\section{ANALYSIS OF PANEL DESIGN BY ABAQUS SOFTWARE}

Abaqus as a general application software having the most advanced two-Dimensional [2], [9]-[11] and three-dimensional structural analysis methods are used for pushover analysis. According to the static analysis of the capabilities of Abaqus program of the pushover, the user can use this kind of analysis to be simple and quick for twodimensional and three-dimensional structures based on the method presented in FEMA-273 and ATC-40 as well. Figure 3 shows a general view of a shear wall without modeled holes in Abaqus Software.

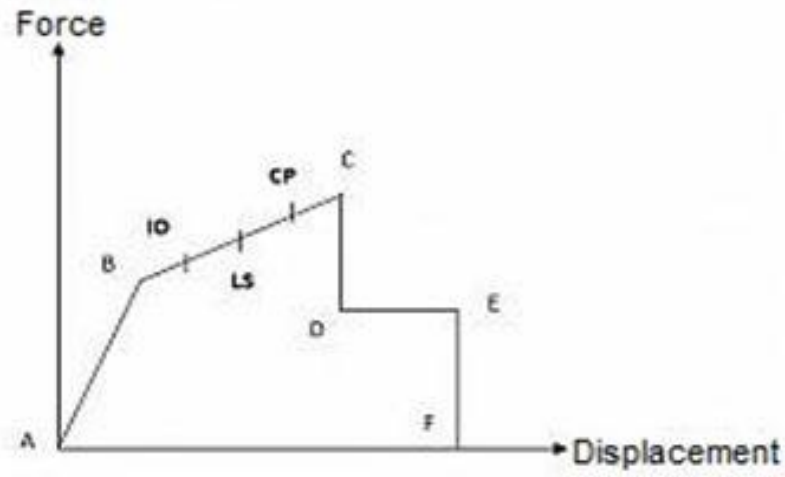

Figure 2 Pushover Curve of the performance of structures [7] 


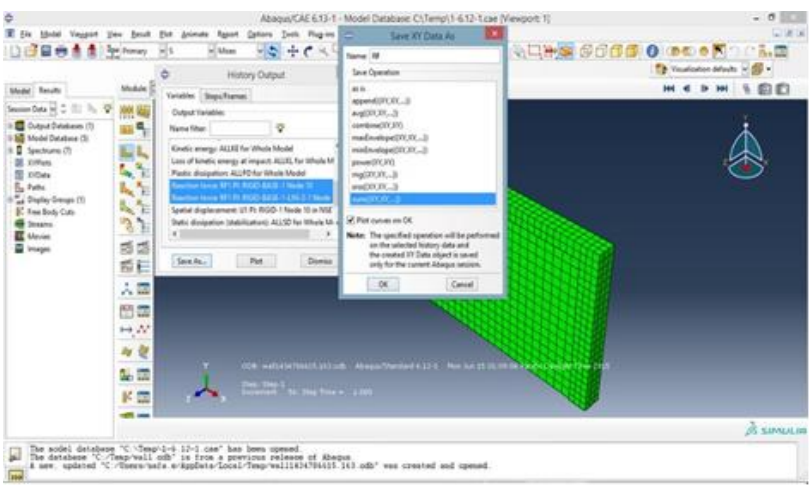

Figure 3 A general view of a shear wall without modeled holes in Abaqus Software

\section{MATERIAL PROPERTIES, DIMENSIONS OF SHEAR WALLS AND OPENINGS IN ABAQUS SOFTWARE MODEL}

As shown in Figures 4 to 6, a 3D shear wall structure is a representative of the lateral system to be modeled in this study with the Abaqus application, and the results have been evaluated.

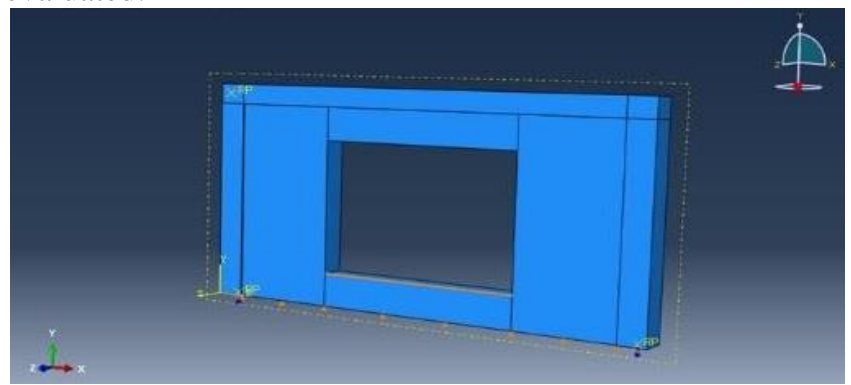

Figure 4 An overview of shear walls with square openings in the Abaqus Software Model

For the longitudinal reinforcement and the transverse reinforcement in the form of $\varnothing 16$ @ 30cm and distance of two networks to each other is $19 \mathrm{~cm}$, and wall thickness is $35 \mathrm{~cm}$. Dimensions of columns around shear walls 40 x 40 and their yokes, in the beginning, is equal to $10 \mathrm{~cm}$ and then increases $15 \mathrm{~cm}$.

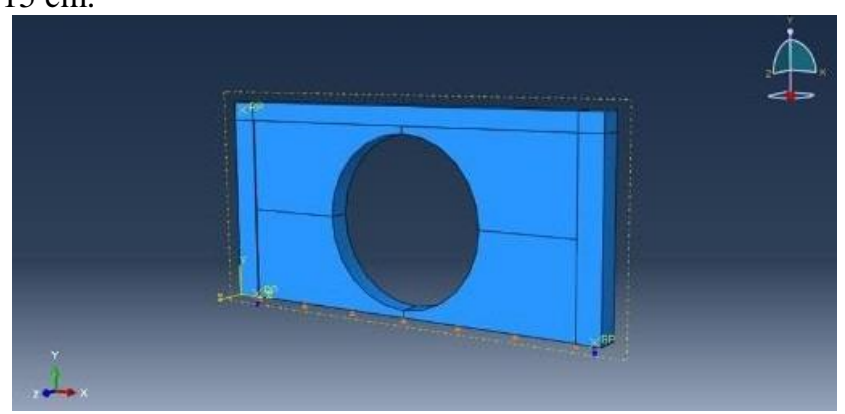

Figure 5 An overview of shear wall with a circular opening in the Abaqus Software Model

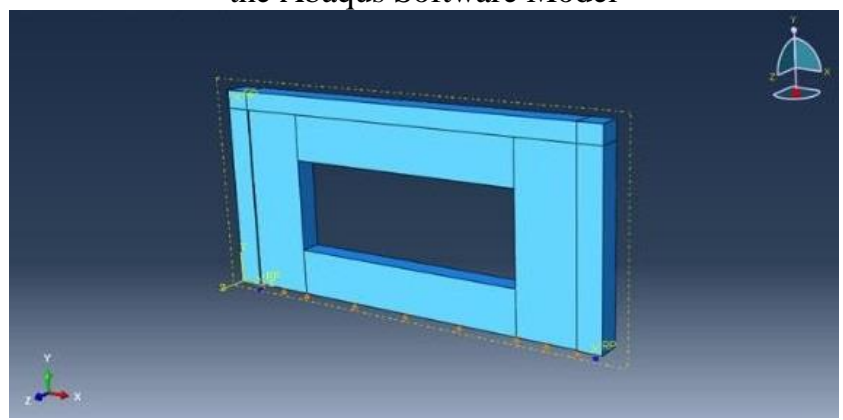

Figure 6 An overview of shear wall with a rectangular opening in the Abaqus Software Model
The height of the wall is 3 meters, and the beam over the wall is $30 \mathrm{x} 40$. The height of the designed wall is 6 meters. The analysis is intended to consider moving to $10 \mathrm{~cm}$ in the plastic (non-linear) area. All models will be account for by a displacement of $10 \mathrm{~cm}$. The opening level is constant in all models equal to one-third of the wall surface area of 6 square meters. In table 1 the Size of openings in shear walls has shown.

Table 1 Size of openings in shear walls

\begin{tabular}{|c|c|c|}
\hline No. & Section names & The dimension of opening $(\mathrm{mm})$ \\
\hline 1 & Wall & 0 \\
\hline 2 & Circle & 1380 \\
\hline 3 & Square & $2450 \times 2450$ \\
\hline 4 & H-rec & $3000 \times 2000$ \\
\hline 5 & H-rec2 & $4000 \times 1500$ \\
\hline
\end{tabular}

To define the profile of concrete, the criteria of concrete damaged plasticity is used because the general behavior and compression of concrete are removed and efficiently simulate concrete situations in the contact between the steel and concrete of the type of contact was buried and used the embedded region. The walls in contact centers are integrated into the column and beam. The staddles are fastened. In up and down not to move and columns act as a pin on the floor (hinged). For the volume model, the C3D8R element is used for modeling. Truss elements for wired models Are used by the specification T3D2 [12]. In table 2, Mechanical properties of concrete materials and in table 3 , mechanical specifications of steel materials (longitudinal and transverse reinforcement) has illustrated.

Table 2 Mechanical properties of concrete materials

\begin{tabular}{|c|c|c|c|c|}
\hline No. & Section names & $\begin{array}{l}\mathrm{E} \\
\left(\mathrm{Kg} / \mathrm{m}^{2}\right)\end{array}$ & $\begin{array}{c}\text { Poisson's } \\
\text { ratio }\end{array}$ & $\begin{array}{c}\text { F'c } \\
\left(\mathrm{Kg} / \mathrm{m}^{2}\right)\end{array}$ \\
\hline 1 & $\begin{array}{c}\text { Wall, Circle, } \\
\text { Square, H-rec, } \\
\text { H-rec2 }\end{array}$ & $2.3 \mathrm{E} 4$ & 0.3 & 210 \\
\hline
\end{tabular}

Table 3 Mechanical specifications of steel materials (longitudinal and transverse reinforcement)

\begin{tabular}{|c|c|c|c|c|}
\hline No. & Section names & $\begin{array}{l}\mathrm{E} \\
\left(\mathrm{Kg} / \mathrm{m}^{2}\right)\end{array}$ & $\begin{array}{c}\text { Poisson's } \\
\text { ratio }\end{array}$ & $\begin{array}{c}\mathrm{F}^{\prime} \mathrm{y} \\
\left(\mathrm{Kg} / \mathrm{m}^{2}\right)\end{array}$ \\
\hline 1 & $\begin{array}{c}\text { Wall, Circle, } \\
\text { Square, H-rec, } \\
\text { H-rec2 }\end{array}$ & $2.1 \mathrm{E} 10$ & 0.3 & 3000 \\
& & & \\
\hline
\end{tabular}

\section{THE RESULTS OF ANALYSIS OF SAMPLES}

\section{A. Study of Charts and Tables of Pushovers Methods Taken of the Sample Analysis}

Looking at the chart of pushover from analysis of samples without opening and an opening with various forms provided in Figure 7, Table 4 shows the comparison of the maximum of load and displacement forced in the samples and Table 5 shows the results multiplied by hardening coefficients of samples, and Table 6 presents the coefficient of added resistance and area under the curve of base cutting-displacement of samples and table 7 also compares the performance levels in the wall with various forms of openings.

Also, in Table 4 Comparison of the maximum load and displacement tolerated in samples and table 5 the result of stiffness factors of samples and in table 6 Added resistance 
coefficient and area under the curve of base cutting-displacement samples and in table 7 Comparison of the performance of different forms of openings in the wall has shown.

\section{B. Evaluation of Ductility and Hardness}

In Figure, 8-a Comparison diagram of ductility of the shear wall has been indicated, and Figure 8-b is a comparison of shear walls' hardness regarding openings' shape.

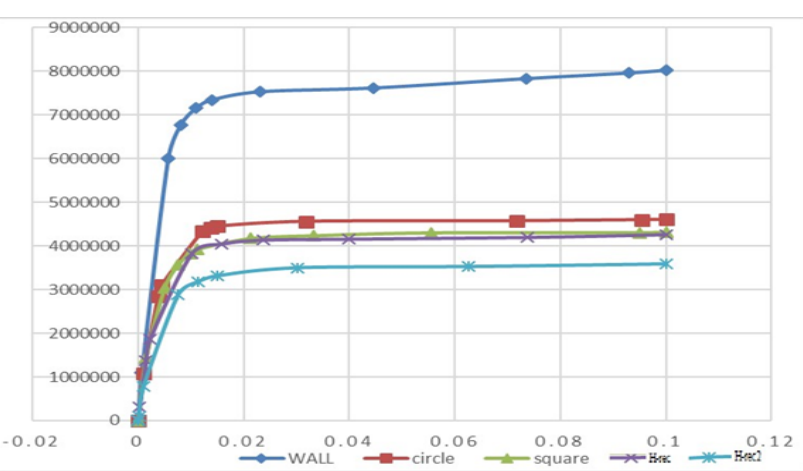

Figure 7 Comparison curve of the pushover charts of shear wall concerning the openings forms in the wall

Table 4 Comparison of the maximum load and displacement tolerated in samples

\begin{tabular}{|l|l|l|l|l|}
\hline No. & $\begin{array}{l}\text { Section } \\
\text { names }\end{array}$ & $\begin{array}{l}\Delta \mathrm{u} \\
(\mathrm{mm})\end{array}$ & $\begin{array}{l}\Delta \mathrm{y} \\
(\mathrm{mm})\end{array}$ & $\mu=\Delta \mathrm{u} / \Delta \mathrm{y}$ \\
\hline 1 & Wall & 100 & 10.978 & 9.1 \\
\hline 2 & Circle & 100 & 12.113 & 8.25 \\
\hline 3 & Square & 100 & 11.205 & 8.92 \\
\hline 4 & H-rec & 100 & 10.209 & 9.79 \\
\hline 5 & H-rec2 & 100 & 11.363 & 8.8 \\
\hline
\end{tabular}

Table- V: The result of stiffness factors of samples

\begin{tabular}{|l|l|l|l|l|l|}
\hline No & $\begin{array}{l}\text { Section } \\
\text { names }\end{array}$ & $\mathbf{F u}(\mathbf{N})$ & $\Delta \mathbf{y}(\mathbf{m m})$ & $\mathbf{F y}(\mathbf{N})$ & $\begin{array}{l}\mathbf{K}=\mathbf{F y} / \Delta \mathbf{y} \\
(\mathbf{N} / \mathbf{m m})\end{array}$ \\
\hline 1 & Wall & 8026170 & 10.9782 & 7156490 & 611881 \\
\hline 2 & Circle & 4602520 & 12.1126 & 4329290 & 357420 \\
\hline 3 & Square & 4315730 & 11.2051 & 3925200 & 350304 \\
\hline 4 & H-rec & 4260340 & 10.2089 & 3829660 & 375129 \\
\hline 5 & H-rec2 & 3589370 & 11.3629 & 3183060 & 280127 \\
\hline
\end{tabular}

Table-VI: Added resistance coefficient and area under the curve of base cutting-displacement samples

\begin{tabular}{|l|l|l|l|l|l|}
\hline $\begin{array}{l}\text { No } \\
\cdot\end{array}$ & $\begin{array}{l}\text { Section } \\
\text { names }\end{array}$ & $\mathbf{V y}(\mathbf{N})$ & $\mathbf{V u}(\mathbf{N})$ & $\begin{array}{l}\mathbf{\Omega}= \\
\mathbf{V y}\end{array}$ & $\begin{array}{l}\text { An } \\
(\mathbf{N} . m m)\end{array}$ \\
\hline 1 & Wall & 7156490 & 8026170 & 1.12 & 715076 \\
\hline 2 & Circle & 4329290 & 4602520 & 1.06 & 418716 \\
\hline 3 & Square & 3925200 & 4315730 & 1.01 & 387867 \\
\hline 4 & H-rec & 3829660 & 4260340 & 1.11 & 382753 \\
\hline 5 & H-rec2 & 3183060 & 3589370 & 1.12 & 328228 \\
\hline
\end{tabular}

Table-VII: Comparison of the performance of different forms of openings in the wall

\begin{tabular}{|l|l|l|l|l|l|l|}
\hline $\begin{array}{l}\text { Structural } \\
\text { performance }\end{array}$ & \multicolumn{2}{|l|}{ IQ } & \multicolumn{2}{l|}{ LS } & CP & \\
\hline $\begin{array}{l}\text { Section } \\
\text { names }\end{array}$ & Force & Distance & Force & Distance & Force & Distance \\
\hline wall & 7533510 & 0.023075 & 7834090 & 0.073571 & 7963480 & 0.092896 \\
\hline circle & 4329290 & 0.012113 & 4412320 & 0.013711 & 4596970 & 0.095339 \\
\hline square & 3925200 & 0.011205 & 4169770 & 0.021325 & 4302620 & 0.094991 \\
\hline h-rec & 3829660 & 0.010209 & 4047480 & 0.015902 & 4198520 & 0.07366 \\
\hline h-rec2 & 2887520 & 0.007575 & 3183060 & 0.011363 & 3529980 & 0.062698 \\
\hline
\end{tabular}

C. Evaluation of ultimate load and added resistance factor

In Figure 9-a diagram of comparing shows the increase of the ultimate load in the shear wall in Figure 9-b diagram of comparing the increase added resistant due to the openings.

D. Evaluation of Energy Absorption

Figure 10 compares an increase in energy absorption due to the shear wall frames with openings provided.

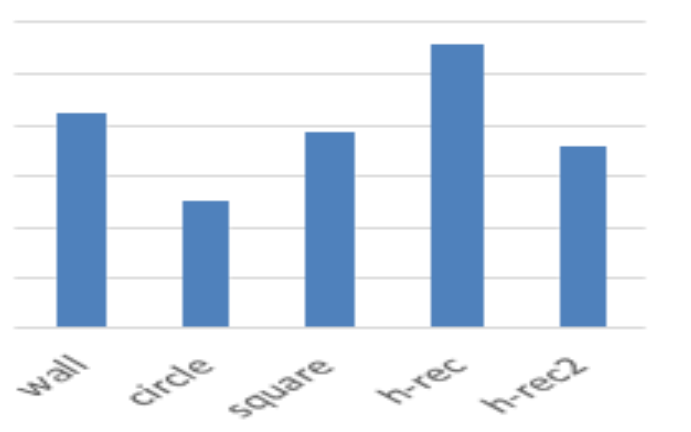

a)

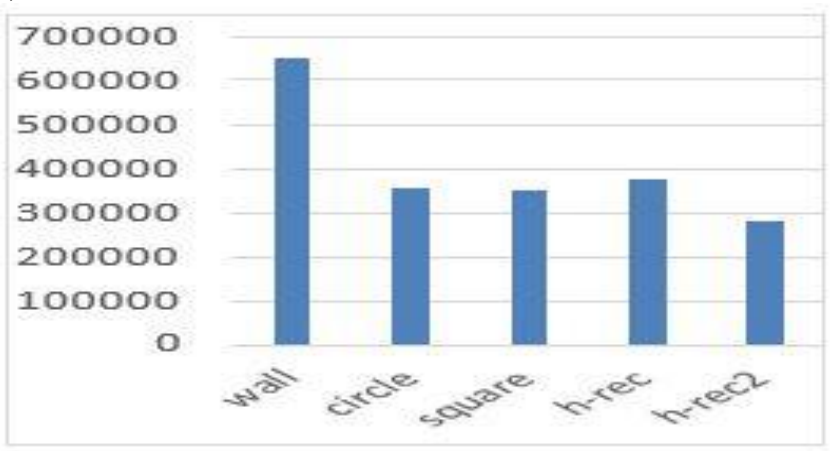

b)

Fig. 8. Diagram of a) ductility comparison, b) hardness comparison

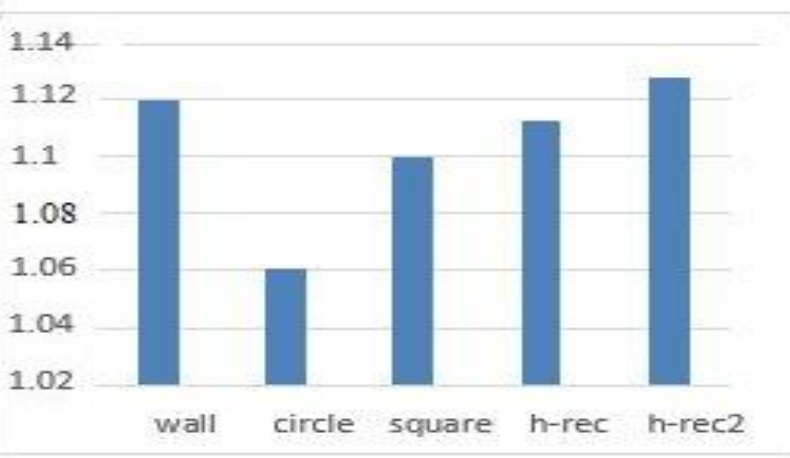

a)

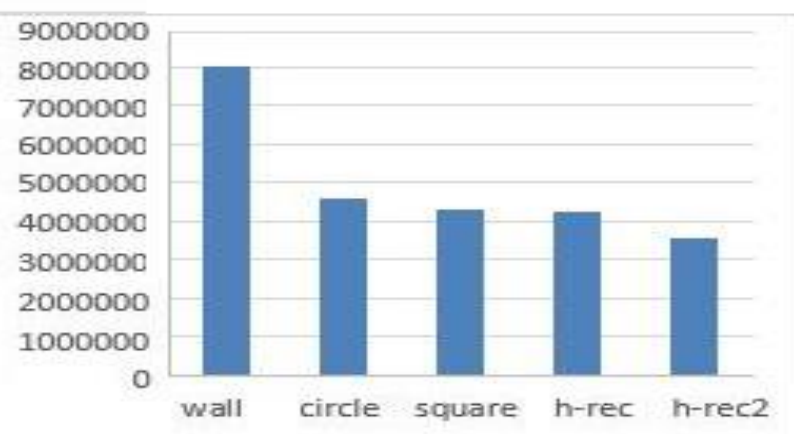

b)

Fig. 9. The graph of increase of a) the ultimate load in the shear wall, b) added resistant due to the openings 


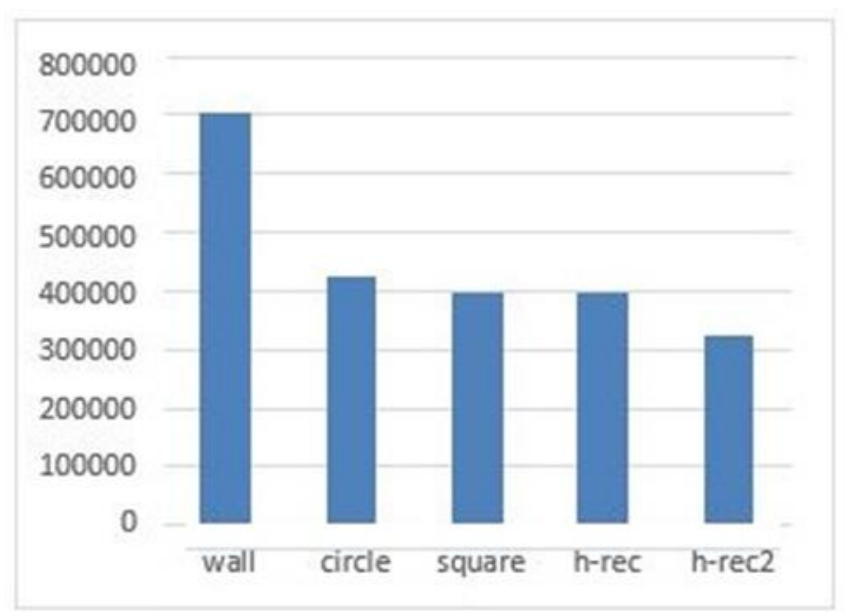

Fig. 10. Diagram of energy absorption in the samples

\section{COMPARISON OF PERFORMANCE LEVELS IN THE SAMPLES WITH OPENINGS}

Fig. 11-a indicates the comparison chart of increasing energy absorbing in the frames with shear wall according to the openings' forms in the comparison chart in Figure 11-b that indicates the energy absorption due to the shear wall frames with openings provided.

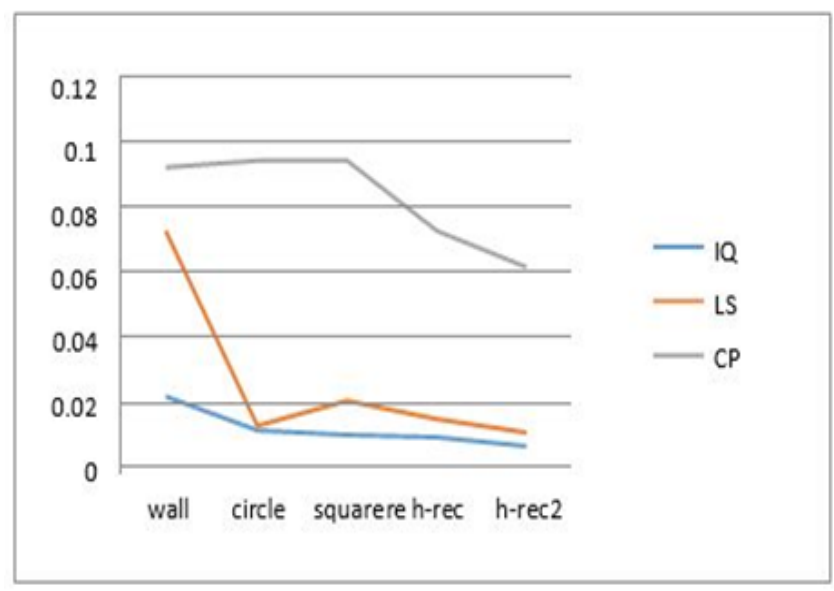

a)

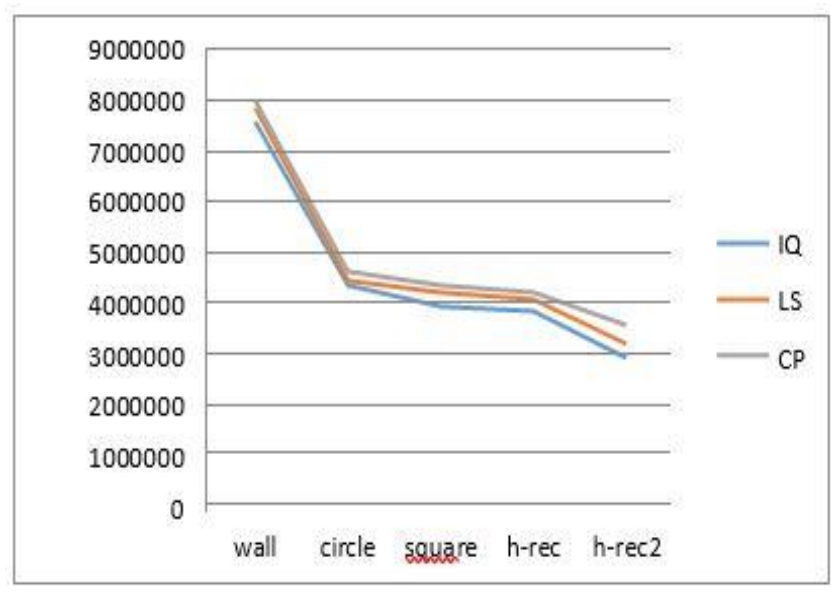

b)

Fig. 11. a) Displacement changes graph in pushover graph for samples and Fig. 11-b Force changes graph in pushover graph for samples

\section{CONCLUSIONS AND DISSECTIONS}

The use of concrete shear wall is recommended according to the many advantages of the energy absorption, difficulty, plasticity and the economic issues related to the construction of the shear walls in the tall, medium and short buildings leads to increase the significant resistance in buildings under construction and in comparison with the flexible frames they will be more economical and have better control for the side skipping the buildings. It may be used from the shear walls beside the bending frame in the manner that the behavior of total structures is soft, resistant, and flexible. In most cases, the shear walls are able to tolerate the highest share of all cutting force that causes a significant increase of the building and significantly reduce severe hearing loss assigned to non-structural elements and also the shear walls are able to tolerate the gravity loads of the building even after the acceptance of many tracks that such columns have no properties and in general such factors made more ensuring than the bending frames.

According to modeling done in the study of wall shear samples, it can be concluded that the openings with various forms affect the resistance and the hardening of samples and based on the results obtained from the diagrams it may be said that the lack of the shear wall harder than the shear wall without the openings is also harder than those with the openings. According to the seismic changes of profiles as well as rectangular samples with different length and width, it can be concluded that the closer the openings are to the edge of the wall the more decrease strength they show.

To create openings in shear walls (in this study the area of openings is equal to 1.3 of total the wall area in accordance with the regulations on the maximum area of the opening in the wall) to reduce the seismic properties of the shear wall so that it will be so reduced at $50 \%$ of all samples on the stiffness, ultimate load, and energy absorption, but the strength and ductility of the reduction is variable depending on the type and form of openings as some of the numeric values to rectangular cross-section of the sample without more openings are these two qualities.

About the openings, those with circular cross-section based on the specifications and model assumptions in the study of the seismic performance better in the final time, energy absorption and stiffness are compared to other forms of openings, but resistance and ductility will be lower.

Given the rectangular cross-section of openings and the same values in both rectangular areas, as long as the lesser the cross-section and the greater the height it is, seismic characteristics such as hardness, ductility, ultimate load and energy absorption than when the opening and height will be less (With identical area ratio in openings).

According to the table and chart, it is specified that the changes of displacement in the levels of uninterrupted operation reduce in case of structures with different forms of shear wall openings than those without openings about 50 percent. However, this decreases to a level more than 4.5 times for the performance of life safety and without reduction for the threshold of structural collapsing for both circular and square sections and about 20 percent of reduction for rectangular section.

It is clear from the table and plot that the force changes at all levels of uninterrupted performance of the operation reduce the safety of life, the threshold of collapsing the 
structures at the samples with different forms of shear well openings than a shear wall without opening with a close approximation to each other about 80 percent.

\section{REFERENCES}

[1] Y. Zhou, D. Zhang, Z. Huang, and D. Li, "Deformation capacity and performance-based seismic design for reinforced concrete shear walls," J. Asian Archit. Build. Eng., vol. 13, no. 1, pp. 209-215, 2014.

[2] H. Alimohammadi and M. Lotfollahi Yaghin, "Study on the Effect of the Concentric Brace and Lightweight Shear Steel Wall on Seismic Behavior of Lightweight Steel Structures," Int. Res. J. Eng. Technol., vol. 6, no. 8, pp. 1358-1362, 2019.

[3] K. Abubakri, "Investigation of the Behavior of Steel Shear Walls Using Finite Elements Analysis," vol. 6, no. 5, pp. 1155-1157, 2016.

[4] S. Mousavi, R. Najafpour, and M. Sheidaii, "Investigating the effect of restraints' configuration on resistance of double layer braced barrel vaults to Progressive collapse," Int. Acad. Inst. Sci. Technol., vol. 6, no. 1, pp. 26-38, 2019.

[5] S. Mousavi, A. Samadi, and O. Azizpour, "Assessing the Behavior of Concrete Moment Frames Reinforced with High-Strength Steel Rebar," J. Emerg. Technol. Innov. Res., vol. 6, no. 6, pp. 271-276, 2019.

[6] S. Mousavi, A. Keramat, and B. Shekasteband, "Investigation of the Effect of Geometric Parameters on Behavior of Special Truss Moment Frames," Int. Res. J. Eng. Technol., vol. 6, no. 7, pp. 1566-1573, 2019.

[7] Y. Mondet and U. Bumann, "Pushover Analysis for the Assessment of Seismic Safety Margins of Auxiliary Buildings," SMiRT 19, pp. 1-8, 2007.

[8] "Performance Based Seismic Design | Expert Commentary | IRMI.com." [Online]. Available: https://www.irmi.com/articles/expert-commentary/performance-b ased-seismic-design. [Accessed: 28-Aug-2019].

[9] H. Alimohammadi and M. Abu-Farsakh, "Finite Element Parametric Study on Rutting Performance of Geosynthetic Reinforced Flexible Pavements," Transp. Res. Board, vol. 98, 2019.

[10] H. Alimohammadi, K. Yashmi Dastjerdi, and M. Lotfollahi Yaghin, "The study of progressive collapse in dual systems," Eng. Arch., pp. 1-10, 2019.

[11] H. Alimohammadi, "Finite element analysis of a Piezoelectric layered plate with different materials," Int. J. Eng. Appl. Sci., vol. 6, no. 7, 2019.

[12] S. Helwany, Applied soil Mechanics with Abaqus applications. 2010.

\section{AUTHORS PROFILE}

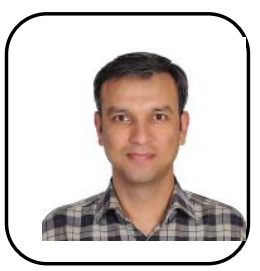

Hossein Alimohammadi has M.SC. in Earthquake Engineering and currently is Geotechnical engineering Ph.D. student at Iowa State University, Iowa, USA.

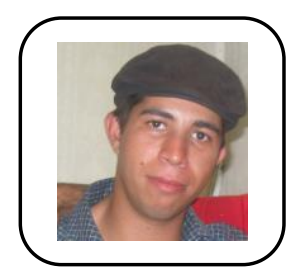

Mostafa Dalvi Esfahani has M.SC. in Earthquake Engineering from Azad University.

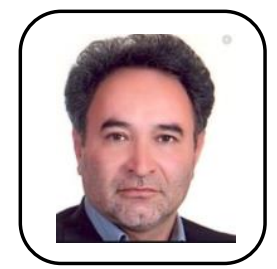

Mohammadali Lotfollahi Yaghin is a professor and President of Azad Maragheh University and Professor of Civil Engineering in Tabriz University, East Azerbaijan, Iran 